

\title{
Fine-grained sediment deposition alters the response of plant CSR strategies on the gravel bars of a highly regulated river
}

Philippe Janssen, Hervé Piégay, André Evette

\section{- To cite this version:}

Philippe Janssen, Hervé Piégay, André Evette. Fine-grained sediment deposition alters the response of plant CSR strategies on the gravel bars of a highly regulated river. Applied Vegetation Science, 2020, 23 (3), pp.452-463. 10.1111/avsc.12494 . hal-03025207

\section{HAL Id: hal-03025207 \\ https://hal.science/hal-03025207}

Submitted on 26 Nov 2020

HAL is a multi-disciplinary open access archive for the deposit and dissemination of scientific research documents, whether they are published or not. The documents may come from teaching and research institutions in France or abroad, or from public or private research centers.
L'archive ouverte pluridisciplinaire HAL, est destinée au dépôt et à la diffusion de documents scientifiques de niveau recherche, publiés ou non, émanant des établissements d'enseignement et de recherche français ou étrangers, des laboratoires publics ou privés. 

regulated river

3

4 Running head: Sedimentation changes CSR strategies

5

6 Philippe Janssen ${ }^{1,2}$, Hervé Piégay ${ }^{2}$, André Evette ${ }^{1}$

7

$8 \quad{ }^{1}$ Univ. Grenoble Alpes, INRAE, LESSEM, F-38402 St-Martin-d'Hères, France

92 Univ. Lyon, UMR 5600 EVS, CNRS, ENS de Lyon, F-69342, Lyon, France

10

$11 *$ Corresponding author, email philippe.janssen@inrae.fr, phone +33 476762879

12

13 Email addresses of other authors:

14 H. Piégay (herve.piegay@ens-Iyon.fr), A. Evette (andre.evette@inrae.fr) 
Aims: In riverine ecosystems, variations in disturbance and stress intensities along the flood gradient shape the community structure. However, human modifications to the flood regime may change the magnitude of disturbance and stress, leading to different species distribution patterns along environmental gradients. We aimed to study the effects of local- and broad-scale environmental gradients on riparian plant CSR strategies along a highly regulated river.

Location: Rhône River, France.

Methods: We assessed how changes in elevation, fine sediment content and annual temperature influenced CSR strategies of riparian communities, by studying variations in CWM and FDis, on gravel bars along a $250 \mathrm{~km}$ north-south river corridor.

Results: Species with contrasting ecological strategies co-occurred less on gravel bars subject to fine sediment deposition, leading to patterns of biotic homogenization along the flood gradients. Furthermore, a shift in CSR strategies from ruderal to stress-tolerant communities was highlighted along the elevation gradient on the bars with low proportions of fine sediments and from stress-tolerant to ruderal communities along the elevation gradient on the bars with high proportions of fine sediments. Regarding the climatic gradient, the ruderal dimension of communities increased with the average temperature. Also, the stress-tolerant dimension of communities diverged between the north and south gravel bars when the proportion of fine sediments was low and converged when the proportion of fine sediments was high.

Conclusions: Overbank fine sedimentation alleviates the intensity of stress along not only the elevation gradient but also the climatic gradient. By homogenizing the functional composition of communities, this process may have detrimental consequences for riparian plants diversity, especially the ruderal pioneer communities in the tidal zone. In regulated river systems, restoration measures should therefore comprehensively integrate an increase in the intensity of (i) disturbance through the reactivation of bedload supply and transport and (ii) stress through increased flow dynamics. ecology, Grime's CSR theory, overbank fine sedimentation, riparian ecology 


\section{INTRODUCTION}

Grime's CSR theory is perhaps one of the most influential niche-based theories of plant community assembly and vegetation succession (Li \& Shipley 2017). This theory proposes to both functionally classify plants and predict changes in the community structure along environmental gradients by focusing on only three dimensions of a ternary ordination plot describing the responses of species to disturbance (i.e., partial or total destruction of biomass) and stress (i.e., external constraints that restrict biomass production) intensities (Grime 1977). Recent advances in functional ecology have shown that the use of three representative leaf traits (i.e., leaf area, leaf dry matter content and specific leaf area) can be used to determine the ecological strategies of plant species in a wide range of ecosystems (Pierce et al. 2017). Through the linkages between leaf traits and CSR functional strategies applied in a unified framework, it now appears possible to quantitatively compare the strategy-environment relationships of vascular plants. Furthermore, by using the ternary coordinates of each species, it become possible to compute a community-wide average strategy (e.g., Li \& Shipley 2017) and thus avoid the use of large categories of plant functional types (Van Bodegom et al. 2012). Overall, this approach gives an empirical link between CSR theory and the functional structure of vegetation, making it possible to compare the strategies of plant communities along environmental gradients and/or in response to humaninduced changes (e.g., Caccianiga et al. 2006; Li \& Shipley 2017).

Riparian zones are transitional areas at the interface between freshwater and terrestrial ecosystems where sharp environmental gradients shape the community structure (Naiman \& Decamps 1997). Due to the variations in disturbance (i.e., flood regime) and stress (i.e., soil moisture and nutriments) intensities from the lower to the upper parts of banks, these dynamic ecosystems encompass a wide variety of habitat geomorphology, which induces niche differentiation and a shift in trait values (Blom 1999; Lytle \& Poff 2004; Steiger et al. 2005). As a result, predictable successional pathways are usually reported along elevation gradients from ruderal to competitor life strategies (Kyle \& Leishman 2009; McCoy-Sulentic et al. 2017). However, the alteration of the flow and sediment regimes of most rivers worldwide has led to changes in the response of riparian plant species guilds to the flood gradient (Bejarano et al. 2018; Aguiar et al. 2018). Indeed, flow regulation induces a decrease in the intensity and magnitude of the inundation regime (Poff et al. 1997; Poff et al. 2007), which limits the destruction of plant biomass by scouring and thus favors vegetation encroachment by drought-adapted species (Merritt \& Poff 2010; González et al. 2010; Nadal-Sala et al. 2017). Moreover, a low level of disturbance may prevent remobilization of coarse-grained alluvial sediments but 
promote the deposition of the solid suspended load by gravitation, i.e. fine-grained alluvial sediments (Wilkes et al. 2019). Accretion of fine sediments increases the water-holding capacity and nutrient availability (Steiger \& Gurnell 2003; Asaeda \& Sanjaya 2017), thereby reducing the intensity of stress along local environmental gradients and promoting an increase in net primary production of vegetation (Asaeda \& Rashid 2012).

Beyond the direct influence of human activity on local-scale environmental gradients, climate change has been emphasized as a major threat to riparian communities (Perry et al. 2012; Garssen et al. 2017). Temperature increase are expected to increase the intensity of stress along flood gradients, inducing growth reductions and dieback of riparian vegetation (Ström et al. 2012; Rivaes et al. 2013; Stella, Riddle, et al. 2013). Moreover, changes in precipitation may increase the magnitude and frequency of flood events, amplifying the alteration of the disturbance regime in rivers, eventually leading to shifts in plant species composition (Garssen et al. 2015; Garssen et al. 2017). These modifications to disturbance and stress intensities over a large scale may further interact with local-scale gradients and exacerbate the related environmental changes, for example, by increasing the intensity of stress along the elevation gradient in riparian zones located in warm climates. As such, it has been shown that riparian plant communities respond consistently to local-scale hydrologic changes and broad-scale climatic changes (Butterfield et al. 2018). This finding suggests that environmental changes related to human activity at different scales may have cumulative effects on the structure and dynamics of plant communities. However, despite the importance of understanding plant responses to human-induced changes in shaping future vegetation, to the best of our knowledge, no empirical studies have yet investigated the relationship between plant CSR strategies and multiple environmental gradients in riparian zones. We aimed to study the effects of elevation and fine-grained deposition gradients on riparian plant CSR strategies along the highly regulated Rhône River. By focusing on gravel bars that are more or less subjected to overbank fine sedimentation along a $250 \mathrm{~km}$ north-south river corridor, we further aimed to understand whether the response of riparian plant strategies to local environmental gradients is mediated by a broad climatic gradient. Specifically, we tested whether and how the community-weighted mean values $\left(\mathrm{C}_{\mathrm{CWM}}, \mathrm{S}_{\mathrm{CWM}}\right.$ and $\left.\mathrm{R}_{\mathrm{CWM}}\right)$ and the functional dispersion values $\left(\mathrm{C}_{\mathrm{FDis}}, \mathrm{S}_{\mathrm{FDis}}\right.$ and $\left.\mathrm{R}_{\mathrm{FDis}}\right)$ were influenced by elevation level, the proportion of fine sediments and the mean annual temperature. The mean value (i.e., average CSR values of all species co-occurring in the community) expresses the dominant value of CSR strategy along environmental gradients, while the dispersion value (i.e., the range of CSR values exhibited by species in the community) expresses the extent of CSR differences among co-occurring species. Analytical strategies that combine both 
measures have been showed to describe two complementary aspects of the relationship between community structure and ecosystem functioning: (i) shifts in trait values due to environmental selection and (ii) patterns of trait convergence or divergence due to niche differentiation (Ricotta \& Moretti 2011; de Bello et al. 2013). Within this framework, we explored the following three hypotheses based on Grime's CSR theory:

(1) Competitors increase from low to high proportions of subsoil fine sediments at middle to high elevations along the northern gravel bars in the Rhône corridor (i.e., low disturbance with low stress);

(2) Stress-tolerators increase from high to low proportions of subsoil fine sediments at middle to high elevations along the southern gravel bars of the Rhône corridor (i.e., low disturbance with high stress);

(3) Ruderals increase from high to low elevations, regardless of the proportion of subsoil fine sediments and the mean annual temperature (i.e., high disturbance with low stress).

\section{MATERIALS \& METHODS}

\section{Study area and experimental design}

The study was carried out along the Rhône River (total length $=810 \mathrm{~km}$, catchment area $=96,500 \mathrm{~km}^{2}$, mean annual discharge $=1,700 \mathrm{m3} / \mathrm{s}$ ) in its middle reach (Figure 1 ). This area is characterized by a temperate climate with mean annual temperatures and precipitation of $13.6^{\circ} \mathrm{C}$ and $755 \mathrm{~mm}$ in the southern part and $11.6^{\circ} \mathrm{C}$ and $815 \mathrm{~mm}$ in the northern part of the study area. Two historical development phases have greatly altered the functioning of this large river: (i) during the $19^{\text {th }}$ century, a rectification phase, characterized by the building of a vast system of longitudinal submersible and transversal dikes in the main channel, was carried out to facilitate navigation; (ii) in the second half of the $20^{\text {th }}$ century, a derivation phase, characterized by the construction of a series of lateral canals, running parallel to the natural Rhône River channel, was carried out to produce hydropower and facilitate irrigation and navigation (for details see, Bravard and Gaydou 2015). These two development phases induced significant impacts in the bypassed sections (i.e., part of the historical Rhône River channel), including changes to the hydrological regime (i.e., a reduction in the frequency and magnitude of the peak flows, Vázquez-Tarrío et al. 2019), channel dewatering, incision and lateral stabilization. These reaches also underwent a bedload supply interruption, with gravel winnowing and bed armoring; thus, present-day bedload transport is limited to fine-grained sediments (Vázquez-Tarrío et al. 2019). Currently, the bypassed sections are characterized by a minimum flow that is observed most of the year until the hydropower plant capacity is reached. 

bypassed sections of the Rhône riverbed, i.e., coarse sediments are no longer remobilized during flood events and are subject to fine-grained overbank sedimentation and colonization by trees. To prevent encroachment of implemented by river managers to scrap woody vegetation by either brush clearing ( $n=7$, in the north) or plowing $(n=8$, in the south).

On each gravel bar, the vegetation was surveyed along three transects spaced at a distance of approximately $100 \mathrm{~m}$ from each other (Figure 1). Transects were positioned perpendicular to the river in areas with clear elevation gradients relative to the water surface (means $\pm S D=1.16 \pm 0.85 \mathrm{~m}$; range $=0.04-3.84 \mathrm{~m}$ ). Transect length varied from $30 \mathrm{~m}$ to $105 \mathrm{~m}$, depending on the width of the gravel bar. The gradients started at the water line and ended before the alluvial floodplain, which was mostly occupied by riparian forest. Along each transect, four $5 \times 5 \mathrm{~m}$ quadrats $\left(25 \mathrm{~m}^{2}\right)$ were positioned for a total of 12 quadrats per gravel bar. The quadrats were positioned in visually homogenous areas while avoiding the aquatic parts of the river margin. Within each quadrat $(n=180)$, all vascular plants were surveyed following Braun-Blanquet abundance/dominance methodology. Because gravel bars along the Rhône River were repeatedly cleared, tree and shrub layers were systematically absent and vegetation surveys were conducted by considering the herbaceous layer only. To characterize the entire plant community and account for plant phenology, two complete surveys were conducted each year (June and July), and to limit observer biases, all surveys were performed by the first author (PJ).

\section{Riparian plant ecological strategies}

For each plant species, the ternary coordinates, i.e., C-dimension, S-dimension and R-dimension values within the triangular CSR ordination, were extracted from the list of plant species $(n=3068)$ available in Pierce et al. (2017, Appendix S1). The ternary coordinates were originally calculated using a global CSR analysis tool that necessitates the use of only three representative and easily measured leaf traits: leaf area, leaf dry matter content and specific leaf area (for details see, Pierce et al. 2017). Among the 233 plant species assessed in our study, the ternary coordinates of 179 species were documented in Pierce et al. (2017). For the missing values, 

singletons) and/or exhibited low vegetation cover. Within each quadrat, we then computed (i) the communityweighted means (CWMs) of the CSR values (hereafter, $\mathrm{C}_{\mathrm{CWM}}, \mathrm{S}_{\mathrm{CWM}}, \mathrm{R}_{\mathrm{CWM}}$ ) and (ii) the functional dispersion (FDis) of the CSR values (hereafter, $C_{F D i s}, S_{F D i s}, R_{F D i s}$ ) (FD package, Laliberté et al. 2014). CWM is defined as the mean of the CSR values weighted by the relative cover of each species bearing each value (Lavorel et al. 2008). FDis is defined as the mean distance of individual species to the weighted centroid of all species in the assemblage (Laliberté \& Legendre 2010).

\section{Environmental gradients}

The elevation and fine-grained deposition gradients were assessed in the field at the center of each quadrat. The relative elevation above the water line was characterized using topographical surveys. Topographical measurements were conducted using a laser rangefinder (TruPulse 200X) positioned on a tripod at a constant height of $1.20 \mathrm{~m}$ and a target at a height of $2 \mathrm{~m}$. The horizontal distance between the tripod and the target was measured between the water line at the beginning of each transect and the center of four successive quadrats. The fine-grained deposition was derived from two soil core samples (30-cm depth) collected in two representative areas within each quadrat and pooled together. Each composite soil sample was then dried, weighed and sieved in the laboratory to estimate the proportion of fine sediments (i.e., $<250-\mu \mathrm{m}$ mesh). The temperature gradient was derived from the WorldClim climatic model (Hijmans et al. 2005). The mean annual temperature was averaged for each plot over the period 1970-2000 and adjusted for the effect of altitude following Zimmermann and Kienast (1999).

\section{Statistical analysis}

178 The continuous independent variables (Appendix S2) were the elevation difference (denoted "Elevation" in 179 tables and figures), the proportion of fine sediments (denoted "Sediments") and the mean annual temperature 180 (denoted "Temperature"). Because the independent variables were measured on different units and because we were interested in interpreting the main effects of the continuous variables in the presence of interactions,

182 the elevation and temperature variables were scaled (Schielzeth 2010), and the sediment variable (i.e., proportional data) was logit transformed prior to the analyses. The dependent variables were the community mean values (i.e., CWM) and the functional dispersion values (i.e., FDis) of the plant ecological strategies in each quadrat. 
We used a modeling approach to determine whether elevation and fine-grained deposition gradients shape riparian plant strategies and to what extent the changes in temperature induced changes in the responses of plants to the local environmental gradients along the Rhône River. We considered a set of 13 a priori models, testing the main and interaction effects between elevation, sediments and temperature variables, plus a null model. Because the quadrats located on the same gravel bar may have a high chance of sharing similar plant species, we used linear mixed models (LMMs) in with "transect" was nested in "gravel bar" $(n=15)$ and included as a random effects (Ime4 package, Bates et al. 2015). Also, because maintenance measures on gravels bars is confounded with the temperature variable, i.e., bars in the north were maintained by brush clearing while bars in the south were maintained by plowing, we included "management" factor as a covariate in all the a priori models. We then fitted normal $L M M s$ for $\mathrm{C}_{\mathrm{CWM}}, \mathrm{S}_{\mathrm{CWM}}, \mathrm{R}_{\mathrm{CWM}}$ and $\mathrm{C}_{\mathrm{FDis}}, \mathrm{S}_{\mathrm{FDis}}, \mathrm{R}_{\mathrm{FDis}}$ dependent variables. In all candidate models, the variance inflation factor among elevation, sediments and temperature variables was below three, indicating a lack of collinearity. The variance explained by the models was estimated using the marginal coefficient of determination for the fixed effect parameters alone (Nakagawa \& Schielzeth 2013). To identify the most parsimonious regression model, we used Akaike's information criterion corrected for small sample sizes (Burnham \& Anderson 2002). Moreover, we used model averaging to estimate the parameters and associated unconditional standard errors based on the subset of the top-ranking models for which the sum of the AICc weights reached $\geq 0.95$ (MuMIn package, Barton 2015). Analyses were performed with R version 3.5.1 (R Core Team 2019).

Overall, 233 plant species (mean $\pm S D=25.3 \pm 10.7$ ) were recorded in the 180 quadrats along the Rhône River: 32 species ( $3.5 \pm 1.9$ ) were competitors (i.e., species C-dimensions > $50 \%)$, 39 species $(4.1 \pm 2.4)$ were stresstolerators (i.e., species S-dimensions > $50 \%$ ), 84 species $(6.8 \pm 4.2)$ were ruderals (i.e., species R-dimensions > $50 \%), 62$ species were not related to a dominant strategies $(10.5 \pm 4.5)$, while 17 species were discarded (Appendix S1).

\section{Influence of environmental gradients on the community-weighted mean values of CSR plant strategies} For the CWM values, $\mathrm{C}_{\mathrm{CWM}}$ was best predicted by the "Sediments" model only, $\mathrm{S}_{\mathrm{CWM}}$ was best predicted by the interaction model "Elevation + Temperature*Sediments" while $\mathrm{R}_{\mathrm{CWM}}$ was best predicted by the interaction 

the variables influencing $\mathrm{C}_{\mathrm{CWM}}\left(\mathrm{N}_{\text {models }}=11\right), \mathrm{S}_{\mathrm{CWM}}\left(\mathrm{N}_{\text {models }}=11\right)$ and $\mathrm{R}_{\mathrm{CWM}}\left(\mathrm{N}_{\text {models }}=10\right)$ (i.e., based on sum of the AICc weights, see Appendix 3). The estimated parameters and related confidence intervals (Table 2) showed that an increase in temperature induced a significant increase in $R_{c w m}$ values. The interaction between elevation and sediments significantly influenced the values of $\mathrm{S}_{\mathrm{CWM}}$ and $\mathrm{R}_{\mathrm{CWM}}$, while the interaction between sediments and temperature significantly influenced the value of $\mathrm{S}_{\mathrm{cwm}}$. A graphical interpretation revealed that $\mathrm{S}_{\mathrm{CWm}}$ increased with elevation when the proportion of fine sediments was low but decreased when the proportion of fine sediments was high; the value of $R_{c w m}$ decreased with elevation when the proportion of fine sediments was low but increased when the proportion of fine sediments was high (Figure 2). Additionally, $\mathrm{S}_{\mathrm{cw}}$ increased with the proportion of fine sediments when the temperature was high but decreased when the temperature was low (Figure 4).

Influence of environmental gradients on the functional dispersion values of CSR plant strategies

For the FDis values, $\mathrm{C}_{\mathrm{FDis}}$ was best predicted by the "Sediments" model only, $\mathrm{S}_{\mathrm{FDis}}$ was best predicted by the interaction model "Elevation + Temperature*Sediments" while $\mathrm{R}_{\mathrm{FDis}}$ was best predicted by the interaction model "Elevation*Sediments". The goodness of fit of these models ranged from $10.4 \%$ to $14.8 \%$ (Table 1), and model selection uncertainty remained since none of the top-ranking models showed strong support to explain the functional dispersion values. We therefore used model averaging to draw inferences about the variables influencing $\mathrm{C}_{\mathrm{FDis}}\left(\mathrm{N}_{\text {models }}=8\right), \mathrm{S}_{\mathrm{FDis}}\left(\mathrm{N}_{\text {models }}=6\right)$ and $\mathrm{R}_{\mathrm{FD} \text { is }}\left(\mathrm{N}_{\text {models }}=4\right)$ (see Appendix 3). The estimated parameters and related confidence intervals (Table 2) showed that an increase in the proportion of fine sediments induced a significant decrease in $\mathrm{C}_{\mathrm{FDis}}$ values. The interaction between elevation and sediments significantly influenced the values of $\mathrm{S}_{\mathrm{FDis}}$ and $\mathrm{R}_{\mathrm{FDis}}$, the interaction between elevation and temperature significantly influenced the value of $R_{F D i s}$, while the interaction between sediments and temperature significantly influenced the value of $\mathrm{S}_{\mathrm{FDis}}$. A graphical interpretation revealed that $\mathrm{S}_{\mathrm{FD} \text { is }}$ and $\mathrm{R}_{\mathrm{FD} \text { is }}$ values increased with elevation when the proportion of fine sediments was high but decreased when the proportion of fine sediments was low (Figure 2). temperature was low (Figure 3), while $\mathrm{S}_{\mathrm{FDis}}$ decreased more rapidly with the proportion of fine sediments when the temperature was low (Figure 4). 
We determined whether riparian plant strategies responded to both local- and broad-scale environmental gradients in a large, regulated river, using the quantitative values of the CSR triangle dimensions (Pierce et al. 2017). We showed that elevation differences and the proportion of fine sediments had non-independent effects on the plant strategies and specifically that fine-grained sediment deposition induced shifts in the responses of stress-tolerant and ruderal communities to the flood gradient on the gravel bars. At a broad scale, variations in climatic conditions along the studied north-south reach induced an increase in the ruderal dimension of the plant communities along the southern gravel bars. However, overbank sedimentation mitigated the effect of the climatic gradient by promoting a less stressful environment (i.e., increasing waterholding capacity and nutrient availability), thus homogenizing the functional composition of the plant communities on bars with high proportions of fine sediments. Overall, this shows that fine-grained sediment deposition alleviates the intensity of stress along not only local flood gradients but also broad climatic gradients, with potential detrimental consequences for riparian biodiversity conservation. Fine-grained sediment deposition induces a shift in plant strategies along the flood gradient Contrary to the hypothesis, CSR plant strategies were not structured in a predictable manner at the local scale. Indeed, the dispersion values for stress-tolerant species increased at low elevations (i.e., co-occurring species in low elevation communities exhibited a larger range of S-values), while the mean and dispersion values for ruderal species increased at high elevations (i.e., co-occurring species in high elevation communities exhibited a larger range of R-values and the average $\mathrm{R}$ value was higher). Given that CSR theory predicts that severely disturbed environments favor rapidly growing plant species that are capable of rapidly producing seeds (Grime 1977), we expected to find the opposite pattern. However, our results also showed that plant strategies were significantly influenced by fine-grained deposition, i.e. that an increase in the proportion of fine sediments induced decreases in the co-occurrence of competitive, stress-tolerant and ruderal species (i.e. in the dispersion values, Table 2). This means that species with contrasting ecological strategies co-occurred less on bars subject to overbank fine sedimentation and thus that this process leads to patterns of biotic homogenization along local environmental gradients (Olden \& Rooney 2006). Specifically, our results highlighted that plant strategies were significantly influenced by the interaction between the fine-grained deposition and elevation level gradients. Indeed, by considering the differences in proportions of fine sediments, we highlighted that the mean and dispersion values for stress-tolerant and ruderal plant species 
changed in opposite direction along the flood gradient. This shift in CSR plant strategies from low to high elevation levels revealed a restructuring of the local communities in gravel bars subject to fine-grained sediment deposition. Thus, in highly disturbed environments (i.e., at low elevation), gravel bars supported riparian plant communities dominated by ruderal species, while allowing for broader co-occurrence of species with different stress-tolerant and ruderal strategies (i.e., niche differentiation was high). Reversely, on gravel bars where large deposits of fine sediment occur, riparian plant communities at low elevation were dominated by stress-tolerant species and the co-occurrence of species with different stress-tolerant and ruderal strategies was low. Overall, these results demonstrated that, at least along the regulated Rhône River, the intensities of disturbance and stress may significantly vary among gravel bars according to overbank sedimentation, which will strongly change the strategy-environment relationships of the riparian plant communities.

The alterations to flow and sediment regimes by human activities have been shown to substantially degrade the functionality of river ecosystems. Flow regulation by dams is well known to directly reduce the downstream intensity of disturbance, lowering the flood peak and bedload transport (Nilsson \& Berggren 2000; Poff et al. 2007) and limiting the destruction of plant biomass by coarse bed scour and burial disturbances (e.g., Polzin \& Rood 2006; Kui \& Stella 2016). Moreover, a fairly constant minimum flow, as is the case in the bypassed sections of the Rhône River, provides longer periods of growth for plant species (Poff et al. 2007). Simultaneously, a low level of disturbance and an increase in vegetation roughness following encroachment favor the deposition of fine sediments (Wilkes et al. 2019), which indirectly reduces the intensity of stress by increasing the soil water-holding capacity and nutrient availability (Steiger \& Gurnell 2003; Asaeda \& Sanjaya 2017). Altogether, these changes promote environmental homogenization along the flood gradient, which fosters the spread of competitive and stress-tolerant communities made up of perennial species and including few dominant clonal species at low elevations. In turn, perennial vegetation traps and stabilizes fine sediments (Corenblit et al. 2009), further lowering the intensity of stress. Additionally, clonal species such as Phragmites australis and Phalaris arundinacea are known to impede the development of other species by shading and inhibiting their germination through the production of a thick litter layer (Craft 2016), which may lead to changes in biotic interactions at the expense of ruderal species. Thus, despite numerous studies have shown that flow regulation benefits species that allocate resources to vegetative growth or the maintenance of resources, at the expense of species that allocate resources to propagules (e.g., Merritt \& Poff 2010; González et al. 2010; Tonkin et al. 2018; Aguiar et al. 2018), we demonstrated here that this effect was primarily driven 
by fine-grained sediment deposition. We therefore inferred that the shift in CSR strategies we documented on the Rhône River is due to a decrease in the intensity of disturbances, in relation to flow regulation and diversion (Vázquez-Tarrío et al. 2019), and a decrease in the intensity of stress, in relation to the deposition of fine sediments, which deeply altered the successional pathways usually observed in riparian zones.

Nevertheless, it must be kept in mind that the studied riparian communities were moderately explained by the models (i.e., the goodness of fit was always lower than $15 \%$ ). This may indicate not only that other important factors were not accounted for in the analysis but also that environmental homogenization may promote a greater stochastic distribution of species along degraded riparian zones.

\section{Fine-grained sediment deposition mitigates the effect of the climatic gradient}

The climatic gradient directly influenced CSR plant strategies. Indeed, along the north-south Rhône River corridor, we found that an increase in temperature induced an increase in the mean values for ruderal plant species. Given that ruderals are predominantly fast-growing species with an annual life cycle (Grime 1977; Pierce et al. 2017), this result suggests that a warmer climate benefits species better adapted to exploit environments that become intermittently favorable. Accordingly, in semiarid conditions, it has been shown that the richness and cover of annual species increased at drier sites (Stromberg et al. 2009; Reynolds \& Shafroth 2017). This may indicate the vulnerability of riparian communities to climate changes (Perry et al. 2012) through direct changes in temperature and precipitation and indirect modifications to streamflow, i.e., by increasing low-flow events and peak flow magnitudes (Poff et al. 1997). However, related changes in the streamflow components are expected to have greater consequences for riparian vegetation in arid and semiarid areas (Garssen et al. 2014), especially in ephemeral streams (Friedman \& Lee 2002; Stromberg et al. 2017). Indeed, along the regulated Rhône River, a fairly constant minimum flow is ensured all year round. This may temper the effects of climatic variations and explain the absence of an interaction effect between elevation and temperature on the mean value of ruderal communities. Instead, we found that the dispersion values for ruderal species was influenced by the interaction between temperature and elevation, specifically that the co-occurrence of species with different ruderal strategies increases along the elevation gradient with increasing temperatures but tended to decrease with decreasing temperatures. This means that riparian communities on the southern gravel bars harbor a greater diversity of plant strategies, i.e., including both species with a primary ruderal strategy and species with a secondary ruderal strategy. Given that riparian plant species richness is known to increase with drainage size (Kuglerová et al. 2015), we inferred that the interaction 
effect reported herein simply reflects the arrival of new species that progressively increase the species pool with downstream position of gravel bars in the river network. This reveals the difficulty to disentangle the climatic gradient from the longitudinal gradient in riverine ecosystems.

In addition to the ruderal dimension of plant communities, we found that both the mean and dispersion values of stress-tolerant plant species were significantly influenced by the interaction between temperature and the proportion of fine sediments. Specifically, our results show that the dominant value of the stress-tolerant dimension of plant communities diverged between the north and south gravel bars when the proportion of fine sediments was low and tended to converge when the proportion of fine sediments was high. Interestingly, although not significant, the same pattern was observed for the dominant value of the ruderal dimension. This may indicate that in highly regulated rivers, fine-grained sediment deposition mitigates the effect of the climatic gradient, e.g., by promoting less stressful environmental conditions (Steiger \& Gurnell 2003; Asaeda \& Rashid 2012; Asaeda \& Sanjaya 2017). Moreover, we found that the co-occurrence of species with different stress-tolerant strategies decreased with increasing proportion of fine sediments, and that this effect was more pronounced along the northern gravel bars. This shows that fine-grained sediment deposition increases the functional similarity of plant communities across gravel bars, which reduces the species pool. In a context of widespread degradation of riparian zones, overbank fine sedimentation may thus further reduce the adaptability of riparian communities by inducing a selection in plant strategies toward a limited range of values. This is especially true in temperate climates where species are less well-adapted to high levels of stress (e.g. Singer et al. 2013; Stella, Rodríguez-González, et al. 2013) and where this absence of adaptation may render riparian ecosystems highly vulnerable to climate change impacts (Capon et al. 2013). Nevertheless, given that the climatic gradient in this study is unreplicated, caution must be exerted when drawing conclusions about the drivers behind the patterns observed, as they may be confounded with the upstream-downstream axis of the river.

\section{CONCLUSION}

In a recent review, Solari et al. (2016) noted the need to better account for soil properties in models that incorporate the processes that relate riparian vegetation to hydromorphology. By quantitatively comparing the strategy-environment relationships of riparian plants and by considering the individual and interactive effects of elevation and fine-grained deposition along a north-south river corridor depicting a climatic gradient, we 
were able to better explain the processes that shape the distribution of CSR plant strategies on gravel bars. Our

361

362

363 results thus confirm the importance of considering processes that are both directly (i.e., disturbance-related processes) and indirectly (i.e., stress-related processes) linked to the flow regime to better understand the structure and dynamic of riparian communities. More generally, our results lend weight to the idea that finegrained sediment deposition is a fundamental component of the hydrogeomorphic processes that create and maintain riparian habitats (Steiger et al. 2005; Corenblit et al. 2009). Since we used a unified framework to quantitatively compare the strategy-environment relationships of plants (Pierce et al. 2017), it will be interesting to see whether the functional structure of riparian communities responds similarly to environmental gradients in other systems. From a conservation or restoration perspective, riparian communities in highly regulated rivers should benefit from (i) an increase in the intensity of disturbance through the reactivation of bedload supply and transport (Bravard et al. 1999; Beechie et al. 2010), and (ii) an increase in the intensity of stress through an increase in flow variability (e.g., increase flood events and favor instable base-flow) (Greet et al. 2011; Tonkin et al. 2018). These actions would especially benefit the development of ruderal pioneer communities in the tidal zone, which are the most threatened by the overgrowth of competitive and stress-tolerant perennial species.

\section{ACKNOWLEDGEMENTS}

We thank Gilles Favier, Delphine Jaymond and Sophie Labonne for help in the field. This work was cofunded by the Labex DRIIHM, French program "Investissements d'Avenir" (ANR-11-LABX-0010), which is managed by the ANR, the OHM Vallée du Rhône, the Agence de l'eau Rhône Méditerranée Corse and IRSTEA.

\section{REFERENCES}

Aguiar, F.C., Segurado, P., Martins, M.J., Bejarano, M.D., Nilsson, C., Portela, M.M., \& Merritt, D.M. 2018. The abundance and distribution of guilds of riparian woody plants change in response to land use and flow regulation (M.-J. Fortin, Ed.). Journal of Applied Ecology 55: 2227-2240.

Asaeda, T., \& Rashid, M.H. 2012. The impacts of sediment released from dams on downstream sediment bar vegetation. Journal of Hydrology 430-431: 25-38.

Asaeda, T., \& Sanjaya, K. 2017. The effect of the shortage of gravel sediment in midstream river channels on riparian vegetation cover. River Research and Applications 33: 1107-1118. 
Barton, K. 2015. MuMIn: Multi-Model Inference. R package version 1.13.4.

390

391

392

393

394

395

396

397

398

399

400

401

402

403

404

405

406

407

408

409

410

411

412

Bates, D., Mächler, M., Bolker, B., \& Walker, S. 2015. Fitting Linear Mixed-Effects Models Using Ime4. Journal of Statistical Software 67:.

Beechie, T.J., Sear, D.A., Olden, J.D., Pess, G.R., Buffington, J.M., Moir, H., Roni, P., \& Pollock, M.M. 2010. Process-based Principles for Restoring River Ecosystems. BioScience 60: 209-222.

Bejarano, M.D., Nilsson, C., \& Aguiar, F.C. 2018. Riparian plant guilds become simpler and most likely fewer following flow regulation (D. Moreno Mateos, Ed.). Journal of Applied Ecology 55: 365-376.

de Bello, F., Lavorel, S., Lavergne, S., Albert, C.H., Boulangeat, I., Mazel, F., \& Thuiller, W. 2013. Hierarchical effects of environmental filters on the functional structure of plant communities: a case study in the French Alps. Ecography 36: 393-402.

Blom, C.W.P.M. 1999. Adaptations to flooding stress: from plant community to molecule. Plant Biology 1: 261273.

Bravard, J.-P., \& Gaydou, P. 2015. Historical development and integrated management of the Rhône River floodplain, from the Alps to the Camargue delta, France. In Hudson, P.F. \& Middelkoop, H. (eds.), Geomorphic approaches to integrated floodplain management of lowland fluvial systems in North America and Europe, pp. 289-320. Springer New York, New York, NY.

Bravard, J.-P., Landon, N., Peiry, J.-L., \& Piégay, H. 1999. Principles of engineering geomorphology for managing channel erosion and bedload transport, examples from French rivers. Geomorphology 31: 291-311.

Burnham, K.P., \& Anderson, D.R. 2002. Model selection and multi-model inference: a practical informationtheoretic approach, 2nd ed. Springer-Verlag, New York.

Butterfield, B.J., Palmquist, E., \& Ralston, B. 2018. Hydrological regime and climate interactively shape riparian vegetation composition along the Colorado River, Grand Canyon. Applied Vegetation Science 21: $572-$ 583.

Caccianiga, M., Luzzaro, A., Pierce, S., Ceriani, R.M., \& Cerabolini, B. 2006. The functional basis of a primary succession resolved by CSR classification. Oikos 112: 10-20.

Capon, S.J., Chambers, L.E., Mac Nally, R., Naiman, R.J., Davies, P., Marshall, N., Pittock, J., Reid, M., Capon, T., Douglas, M., Catford, J., Baldwin, D.S., Stewardson, M., Roberts, J., Parsons, M., \& Williams, S.E. 2013. Riparian ecosystems in the 21st century: hotspots for climate change adaptation? Ecosystems 16: 359381. 
Corenblit, D., Steiger, J., Gurnell, A.M., Tabacchi, E., \& Roques, L. 2009. Control of sediment dynamics by vegetation as a key function driving biogeomorphic succession within fluvial corridors. Earth Surface Processes and Landforms 34: 1790-1810.

Craft, C. 2016. Creating and restoring wetlands: from theory to practice.

Friedman, J.M., \& Lee, V.J. 2002. Extreme floods, channel change, and riparian forests along ephemeral streams. Ecological Monographs 72: 409-425.

Garssen, A.G., Baattrup-Pedersen, A., Riis, T., Raven, B.M., Hoffman, C.C., Verhoeven, J.T.A., \& Soons, M.B. 2017. Effects of increased flooding on riparian vegetation: Field experiments simulating climate change along five European lowland streams. Global Change Biology 23: 3052-3063.

Garssen, A.G., Baattrup-Pedersen, A., Voesenek, L.A.C.J., Verhoeven, J.T.A., \& Soons, M.B. 2015. Riparian plant community responses to increased flooding: a meta-analysis. Global Change Biology 21: 2881-2890.

Garssen, A.G., Verhoeven, J.T.A., \& Soons, M.B. 2014. Effects of climate-induced increases in summer drought on riparian plant species: a meta-analysis. Freshwater Biology 59: 1052-1063.

González, E., González-Sanchis, M., Cabezas, Á., Comín, F.A., \& Muller, E. 2010. Recent changes in the riparian forest of a large regulated mediterranean River: implications for management. Environmental Management 45: 669-681.

Greet, J., Angus Webb, J., \& Cousens, R.D. 2011. The importance of seasonal flow timing for riparian vegetation dynamics: a systematic review using causal criteria analysis. Freshwater Biology 56: 1231-1247.

Grime, J.P. 1977. Evidence for the existence of three primary strategies in plants and its relevance to ecological and evolutionary theory. The American Naturalist 111: 1169-1194.

Hijmans, R.J., Cameron, S.E., Parra, J.L., Jones, P.G., \& Jarvis, A. 2005. Very high resolution interpolated climate surfaces for global land areas. International Journal of Climatology 25: 1965-1978.

Kuglerová, L., Jansson, R., Sponseller, R.A., Laudon, H., \& Malm-Renöfält, B. 2015. Local and regional processes determine plant species richness in a river-network metacommunity. Ecology 96: 381-391.

Kui, L., \& Stella, J.C. 2016. Fluvial sediment burial increases mortality of young riparian trees but induces compensatory growth response in survivors. Forest Ecology and Management 366: 32-40.

Kyle, G., \& Leishman, M.R. 2009. Plant functional trait variation in relation to riparian geomorphology: The importance of disturbance. Austral Ecology 34: 793-804. 
Laliberté, E., \& Legendre, P. 2010. A distance-based framework for measuring functional diversity from multiple traits. Ecology 91: 299-305.

Laliberté, E., Legendre, P., \& Shipley, B. 2014. FD: measuring functional diversity from multiple traits, and other tools for functional ecology. R package version 1.0-12.

Lavorel, S., Grigulis, K., McIntyre, S., Williams, N.S.G., Garden, D., Dorrough, J., Berman, S., Quétier, F., Thébault, A., \& Bonis, A. 2008. Assessing functional diversity in the field - methodology matters! Functional Ecology 22: 134-147.

Li, Y., \& Shipley, B. 2017. An experimental test of CSR theory using a globally calibrated ordination method. PLOS ONE 12: e0175404.

Lytle, D.A., \& Poff, N.L. 2004. Adaptation to natural flow regimes. Trends in Ecology \& Evolution 19: 94-100. McCoy-Sulentic, M.E., Kolb, T.E., Merritt, D.M., Palmquist, E., Ralston, B.E., Sarr, D.A., \& Shafroth, P.B. 2017. Changes in community-level riparian plant traits over inundation gradients, Colorado River, Grand Canyon. Wetlands 37: 635-646.

Merritt, D.M., \& Poff, N.L.R. 2010. Shifting dominance of riparian Populus and Tamarix along gradients of flow alteration in western North American rivers. Ecological Applications 20: 135-152.

Nadal-Sala, D., Sabaté, S., Sánchez-Costa, E., Poblador, S., Sabater, F., \& Gracia, C. 2017. Growth and water use performance of four co-occurring riparian tree species in a Mediterranean riparian forest. Forest Ecology and Management 396: 132-142.

Naiman, R.J., \& Decamps, H. 1997. The ecology of interfaces: riparian zones. Annual review of Ecology and Systematics 28: 621-658.

Nakagawa, S., \& Schielzeth, H. 2013. A general and simple method for obtaining $\mathrm{R}^{2}$ from generalized linear mixed-effects models. Methods in Ecology and Evolution 4: 133-142.

Nilsson, C., \& Berggren, K. 2000. Alterations of riparian ecosystems caused by river regulation. BioScience 50 : 783.

Olden, J.D., \& Rooney, T.P. 2006. On defining and quantifying biotic homogenization. Global Ecology and Biogeography 15: 113-120.

Perry, L.G., Andersen, D.C., Reynolds, L.V., Nelson, S.M., \& Shafroth, P.B. 2012. Vulnerability of riparian ecosystems to elevated CO2 and climate change in arid and semiarid western North America. Global Change Biology 18: 821-842. 
Pierce, S., Negreiros, D., Cerabolini, B.E.L., Kattge, J., Díaz, S., Kleyer, M., Shipley, B., Wright, S.J., Soudzilovskaia, N.A., Onipchenko, V.G., van Bodegom, P.M., Frenette-Dussault, C., Weiher, E., Pinho, B.X., Cornelissen, J.H.C., Grime, J.P., Thompson, K., Hunt, R., Wilson, P.J., Buffa, G., Nyakunga, O.C., Reich, P.B., Caccianiga, M., Mangili, F., Ceriani, R.M., Luzzaro, A., Brusa, G., Siefert, A., Barbosa, N.P.U., Chapin, F.S., Cornwell, W.K., Fang, J., Fernandes, G.W., Garnier, E., Le Stradic, S., Peñuelas, J., Melo, F.P.L., Slaviero, A., Tabarelli, M., \& Tampucci, D. 2017. A global method for calculating plant CSR ecological strategies applied across biomes world-wide. Functional Ecology 31: 444-457.

Poff, N.L., Allan, J.D., Bain, M.B., Karr, J.R., Prestegaard, K.L., Richter, B.D., Sparks, R.E., \& Stromberg, J.C. 1997. The natural flow regime. BioScience 47: 769-784.

Poff, N.L., Olden, J.D., Merritt, D.M., \& Pepin, D.M. 2007. Homogenization of regional river dynamics by dams and global biodiversity implications. Proceedings of the National Academy of Sciences 104: 5732-5737.

Polzin, M.L., \& Rood, S.B. 2006. Effective disturbance: Seedling safe sites and patch recruitment of riparian cottonwoods after a major flood of a mountain river. Wetlands 26: 965-980.

R Core Team. 2019. R: A language and environment for statistical computing. R Foundation for Statistical Computing, Vienna, Austria.

Reynolds, L.V., \& Shafroth, P.B. 2017. Riparian plant composition along hydrologic gradients in a dryland river basin and implications for a warming climate. Ecohydrology 10: e1864.

Ricotta, C., \& Moretti, M. 2011. CWM and Rao's quadratic diversity: a unified framework for functional ecology. Oecologia 167: 181-188.

Rivaes, R., Rodríguez-González, P.M., Albuquerque, A., Pinheiro, A.N., Egger, G., \& Ferreira, M.T. 2013. Riparian vegetation responses to altered flow regimes driven by climate change in Mediterranean rivers. Ecohydrology 6: 413-424.

Schielzeth, H. 2010. Simple means to improve the interpretability of regression coefficients: Interpretation of regression coefficients. Methods in Ecology and Evolution 1: 103-113.

Singer, M.B., Stella, J.C., Dufour, S., Piégay, H., Wilson, R.J.S., \& Johnstone, L. 2013. Contrasting water-uptake and growth responses to drought in co-occurring riparian tree species. Ecohydrology 6: 402-412.

Solari, L., Van Oorschot, M., Belletti, B., Hendriks, D., Rinaldi, M., \& Vargas-Luna, A. 2016. Advances on modelling riparian vegetation-hydromorphology interactions. River Research and Applications 32: 164-178. 
Steiger, J., \& Gurnell, A.M. 2003. Spatial hydrogeomorphological influences on sediment and nutrient deposition in riparian zones: observations from the Garonne River, France. Geomorphology 49: 1-23.

Steiger, J., Tabacchi, E., Dufour, S., Corenblit, D., \& Peiry, J.-L. 2005. Hydrogeomorphic processes affecting riparian habitat within alluvial channel-floodplain river systems: a review for the temperate zone. River Research and Applications 21: 719-737.

Stella, J.C., Riddle, J., Piégay, H., Gagnage, M., \& Trémélo, M.-L. 2013. Climate and local geomorphic interactions drive patterns of riparian forest decline along a Mediterranean Basin river. Geomorphology 202: 101-114.

Stella, J.C., Rodríguez-González, P.M., Dufour, S., \& Bendix, J. 2013. Riparian vegetation research in Mediterranean-climate regions: common patterns, ecological processes, and considerations for management. Hydrobiologia 719: 291-315.

Ström, L., Jansson, R., \& Nilsson, C. 2012. Projected changes in plant species richness and extent of riparian vegetation belts as a result of climate-driven hydrological change along the Vindel River in Sweden. Freshwater Biology 57: 49-60.

Stromberg, J.C., Lite, S.J., \& Dixon, M.D. 2009. Effects of stream flow patterns on riparian vegetation of a semiarid river: Implications for a changing climate. River Research and Applications. doi: $10.1002 /$ rra.1272

Stromberg, J.C., Setaro, D.L., Gallo, E.L., Lohse, K.A., \& Meixner, T. 2017. Riparian vegetation of ephemeral streams. Journal of Arid Environments 138: 27-37.

Tonkin, J.D., Merritt, David.M., Olden, J.D., Reynolds, L.V., \& Lytle, D.A. 2018. Flow regime alteration degrades ecological networks in riparian ecosystems. Nature Ecology \& Evolution 2: 86-93.

Van Bodegom, P.M., Douma, J.C., Witte, J.P.M., Ordoñez, J.C., Bartholomeus, R.P., \& Aerts, R. 2012. Going beyond limitations of plant functional types when predicting global ecosystem-atmosphere fluxes: exploring the merits of traits-based approaches. Global Ecology and Biogeography 21: 625-636.

Vázquez-Tarrío, D., Tal, M., Camenen, B., \& Piégay, H. 2019. Effects of continuous embankments and successive run-of-the-river dams on bedload transport capacities along the Rhône River, France. Science of The Total Environment 658: 1375-1389. 
531 Wilkes, M.A., Gittins, J.R., Mathers, K.L., Mason, R., Casas-Mulet, R., Vanzo, D., Mckenzie, M., Murray-Bligh, J., 532 England, J., Gurnell, A., \& Jones, J.I. 2019. Physical and biological controls on fine sediment transport and storage in rivers. Wiley Interdisciplinary Reviews: Water 6: e1331.

534 Zimmermann, N.E., \& Kienast, F. 1999. Predictive mapping of alpine grasslands in Switzerland: species versus community approach. Journal of Vegetation Science 10: 469-482.

536 
537 Table 1. Top-ranking models predicting the community-weighted mean values (CWM) and the functional

538 dispersion values (FDis) of CSR plant strategies along the Rhône River (France), as assessed with Akaike's

539 information criterion corrected for small sample size (AICc). Number of parameters (k), AICc, AICc weight (W)

540 and adjusted marginal coefficient of determination $\left(R^{2}\right)$ are provided.

\begin{tabular}{cllcccc}
\hline Measure & \multicolumn{1}{c}{ Variable } & Top-ranked model (fixed effects) & $\mathrm{k}$ & $\mathrm{AlCc}$ & $\mathrm{W}$ & $\mathrm{R}_{\text {marginal }}$ \\
\hline \multirow{3}{*}{ CWM } & Competitive & Sediments & 5 & 1044.7 & 0.267 & 0.041 \\
& Stress-tolerant & Elevation + Temperature*Sediments & 8 & 1243.6 & 0.238 & 0.097 \\
& Ruderal & Temperature + Elevation*Sediments & 8 & 1249.1 & 0.490 & 0.132 \\
\hline \multirow{3}{*}{ FDis } & Competitive & Sediments & 5 & -184.2 & 0.296 & 0.104 \\
& Stress-tolerant & Elevation + Temperature*Sediments & 8 & -66.6 & 0.415 & 0.148 \\
& Ruderal & Elevation*Sediments & 7 & -8.7 & 0.413 & 0.138 \\
\hline
\end{tabular}

541 

coefficients in bold excluded 0 (NA = Not Available, i.e., AICc parameters and associated unconditional standard errors were not part of the top-ranked model).

\begin{tabular}{|c|c|c|c|c|c|c|c|c|c|c|}
\hline \multirow{2}{*}{ Measure } & \multirow{2}{*}{ Variable } & \multicolumn{3}{|c|}{ Elevation } & \multicolumn{3}{|c|}{ Sediments } & \multicolumn{3}{|c|}{ Temperature } \\
\hline & & Imp. & Estimate $( \pm S E)$ & $(95 \% \mathrm{Cl})$ & Imp. & Estimate $( \pm S E)$ & (95\% Cl) & Imp. & Estimate $( \pm \mathrm{SE})$ & $(95 \% \mathrm{Cl})$ \\
\hline \multirow{3}{*}{ CWM } & Competitive & 0.42 & $-0.387( \pm 0.371)$ & $(-1.114 ; 0.340)$ & 0.67 & $-0.272( \pm 0.154)$ & $(-0.575 ; 0.031)$ & 0.30 & $-0.055( \pm 0.874)$ & $(-1.768 ; 1.658)$ \\
\hline & Stress-tolerant & 0.70 & $-1.187( \pm 0.670)$ & $(-2.500 ; 0.126)$ & 0.79 & $0.430( \pm 0.313)$ & $(-0.183 ; 1.043)$ & 0.81 & $-2.325( \pm 1.800)$ & $(-5.852 ; 1.202)$ \\
\hline & Ruderal & 0.95 & $1.562( \pm 0.660)$ & $(0.268 ; 2.855)$ & 0.78 & $-0.202( \pm 0.284)$ & $(-0.758 ; 0.355)$ & 0.87 & $3.119( \pm 1.425)$ & $(0.325 ; 5.912)$ \\
\hline \multirow{3}{*}{ FDis } & Competitive & 0.33 & $-0.005( \pm 0.012)$ & $(-0.028 ; 0.019)$ & 1.00 & $-0.017( \pm 0.006)$ & $(-0.028 ;-0.005)$ & 0.50 & $0.029( \pm 0.028)$ & $(-0.027 ; 0.084)$ \\
\hline & Stress-tolerant & 0.92 & $0.040( \pm 0.017)$ & $(0.007 ; 0.072)$ & 1.00 & $-0.034( \pm 0.009)$ & $(-0.051 ;-0.016)$ & 0.76 & $0.080( \pm 0.042)$ & $(-0.002 ; 0.163)$ \\
\hline & Ruderal & 1.00 & $0.052( \pm 0.020)$ & $(0.013 ; 0.091)$ & 1.00 & $-0.049( \pm 0.010)$ & $(-0.069 ;-0.029)$ & 0.54 & $0.054( \pm 0.039)$ & $(-0.022 ; 0.129)$ \\
\hline \multirow{2}{*}{ Measure } & \multirow{2}{*}{ Variable } & \multicolumn{3}{|c|}{ Elevation*Sediments } & \multicolumn{3}{|c|}{ Elevation*Temperature } & \multicolumn{3}{|c|}{ Sediments*Temperature } \\
\hline & & Imp. & Estimate $( \pm \mathrm{SE})$ & $(95 \% \mathrm{Cl})$ & Imp. & Estimate $( \pm \mathrm{SE})$ & $(95 \% \mathrm{Cl})$ & Imp. & Estimate $( \pm S E)$ & $(95 \% \mathrm{Cl})$ \\
\hline \multirow{3}{*}{ CWM } & Competitive & 0.06 & $-0.096( \pm 0.133)$ & $(-0.356 ; 0.164)$ & NA & NA & NA & 0.07 & $-0.136( \pm 0.154)$ & $(-0.438 ; 0.165)$ \\
\hline & Stress-tolerant & 0.30 & $-0.513( \pm 0.227)$ & $(-0.959 ;-0.068)$ & NA & NA & NA & 0.39 & $0.622( \pm 0.269)$ & $(0.096 ; 1.148)$ \\
\hline & Ruderal & 0.61 & $0.604( \pm 0.232)$ & $(0.150 ; 1.058)$ & 0.07 & $0.299( \pm 0.601)$ & $(-0.878 ; 1.477)$ & 0.09 & $-0.468( \pm 0.268)$ & $(-0.993 ; 0.058)$ \\
\hline \multirow{3}{*}{ FDis } & Competitive & 0.10 & $-0.006( \pm 0.006)$ & $(-0.016 ; 0.005)$ & NA & NA & NA & 0.29 & $0.011( \pm 0.006)$ & $(-0.001 ; 0.023)$ \\
\hline & Stress-tolerant & 0.38 & $0.017( \pm 0.008)$ & $(0.002 ; 0.032)$ & NA & NA & NA & 0.52 & $0.022( \pm 0.009)$ & $(0.005 ; 0.038)$ \\
\hline & Ruderal & 0.80 & $0.025( \pm 0.009)$ & $(0.007 ; 0.042)$ & 0.18 & $0.046( \pm 0.018)$ & $(0.010 ; 0.081)$ & NA & NA & NA \\
\hline
\end{tabular}


547 along the Rhône River and form of the sampling design used to survey riparian plant communities.

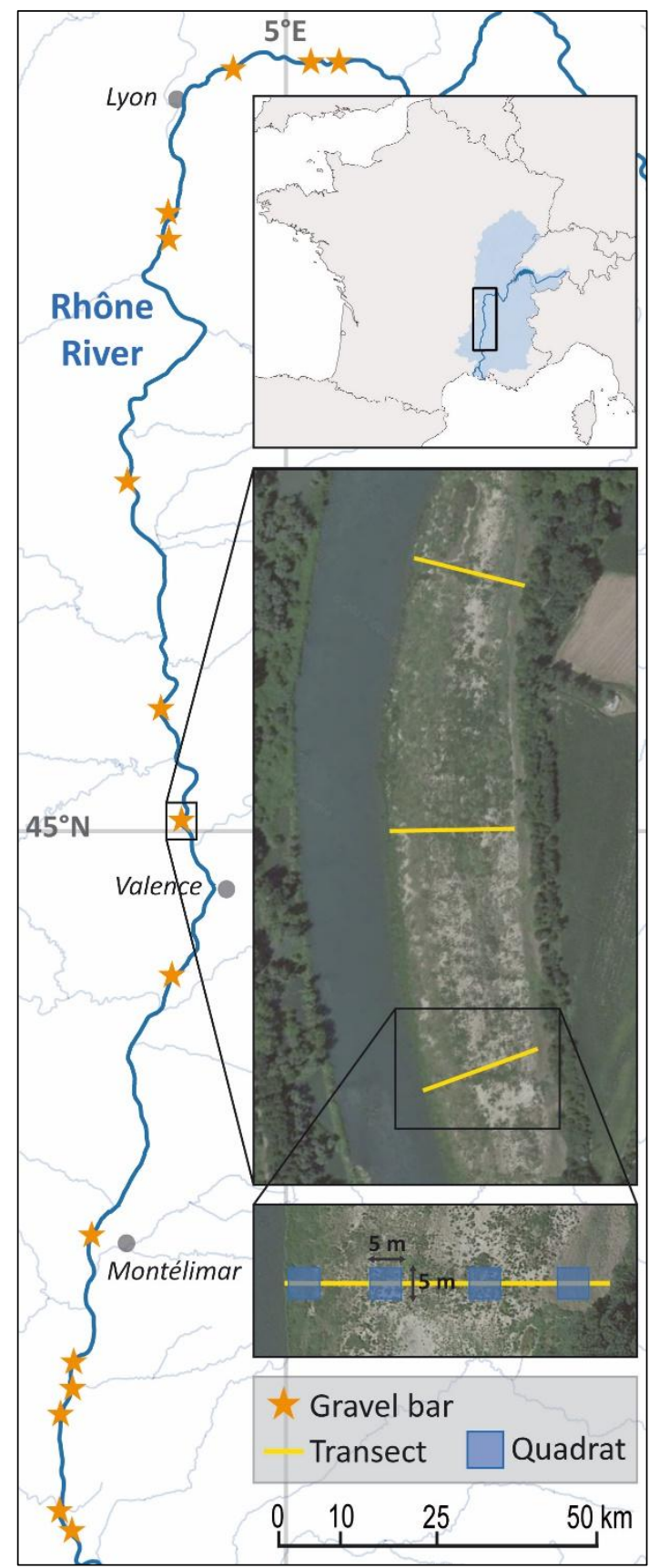


Figure 2. Interaction effect between elevation and sediments in relation to the community-weighted mean

549 values (CWM) and the functional dispersion values (FDis) of CSR plant strategies along the Rhône River

550 (France). To provide representation, the proportion of fine sediments has been divided into two equally sized

551 groups (see Table 2 for statistical significance, n.s. interaction = non-significant interaction).

552 Figure 3. Interaction effect between elevation and temperature in relation to the community-weighted mean

553 values (CWM) and the functional dispersion values (FDis) of CSR plant strategies along the Rhône River

554 (France). To provide representation, the mean annual temperature has been divided into two equally sized

555 groups (see Table 2 for statistical significance, n.s. interaction = non-significant interaction).

557 values (CWM) and the functional dispersion values (FDis) of CSR plant strategies along the Rhône River

558 (France). To provide representation, the mean annual temperature has been divided into two equally sized

559 groups (see Table 2 for statistical significance, n.s. interaction = non-significant interaction).
